\title{
Hematology Test
}

National Cancer Institute

\section{Source}

National Cancer Institute. Hematology Test. NCI Thesaurus. Code C49286.

A laboratory test to measure hematopoietic components and investig ate hematologic disorders in a blood sample. 